\title{
FORMAÇÃO DE PROFESSORES: CÔNCAVO E CONVEXO
}

\author{
Teacher Formation: Concave And Convex \\ Formación de Profesores: cóncavo y convexo
}

\section{Maria José de Pinho ${ }^{1}$ Elzimar Pereira Nascimento Ferraz ${ }^{2}$}

\begin{abstract}
RESUMO: O texto propõe uma reflexão acerca da formação de professores da educação básica. Discute algumas contradições na oferta do modelo de formação posto, como a questão da pesquisa enquanto discurso de formar professor-pesquisador em oposição ao currículo dos cursos no qual o desenvolvimento de pesquisas está ausente. Tem como fio condutor o diálogo sobre formação de professores enquanto imagens côncavas e convexas, no sentido de entender as imagens, reais ou virtuais produzidas pelas instituições. No primeiro momento o artigo aponta algumas inquietações com relação às políticas públicas de cursos de graduação e no segundo momento aborda a formação enquanto processo de valorização profissional tendo a crítica e a ética enquanto pilares formativos.
\end{abstract}

Palavras-chave: Educação Básica. Cursos de Graduação. Formação de Professores.

\section{PRIMEIRAS PALAVRAS}

Esta é uma escrita em dupla, duas mentes com uma mesma inquietação: qual é a imagem que temos sobre a formação de professores na atualidade?

Com o processo de democratização brasileira e das novas perspectivas educacionais, desde os anos 1980 e, com maior intensidade na primeira década de 2000, vem aumentando o acesso à educação básica.

Questões sobre a vida profissional emergem. Uma delas refere-se ao despreparo dos professores, cuja formação de cunho tradicional, é destoante das atuais exigências educacionais para a prática pedagógica como, por exemplo, a necessidade de elaborar projetos interdisciplinares.

Os cursos de formação de professores passam por transformações que visam proporcionar maior qualidade ao trabalho profissional docente. Contudo, uma revisão na formação em nível superior não é suficiente para garantir a boa atuação profissional. Faz-se

\footnotetext{
${ }^{1}$ Doutora em Currículo e Educação pela Pontifícia Universidade Católica de São Paulo (PUC- SP). Professora do Mestrado e Doutorado em Ensino de Língua e Literatura e do Mestrado em Educação da Universidade Federal do Tocantins. E-mail: mjpgon@uft.edu.br.

${ }^{2}$ Doutora em Educação pela Universidade Federal de Goiás/UFG. Professora da Universidade Federal do Tocantins. Coordenadora do Programa de Formação de Professores do Curso de Matemática, Campus de Araguaína/PARFOR. E-mail: elzimar@uft.edu.br.
} 
necessária mudança substancial na estrutura de trabalho, além de uma ação mais expressiva dos sindicatos e do poder público na política de cargos e salários.

Esse texto tem como pressuposto o diálogo sobre formação de professores enquanto imagens côncavas e convexas ${ }^{3}$, no sentido de elucidar o aparecimento dessas imagens na esfera legal das políticas públicas.

Segundo a filosofia mecanicista, as sensações produzem na mente as causas dos movimentos dos corpos externos. Logo, as palavras só tem significado quando associadas às sensações. A verdade consiste no ordenamento correto de nomes e sensações e as definições são fundamentais. A razão equivale ao cálculo e é correta quando os signos se vinculam com as imagens. Causas e efeitos constituem um reflexo direto do mundo. Portanto, o caminho para a verdade passa pela definição clara de um método científico, reforçando a idéia do côncavo e convexo.

O texto também navega na esfera pedagógica da prática cotidiana da sala de aula. Busca alguns elementos importantes a serem contemplados como a criticidade e a ética enquanto pilar da atividade docente. Esta reflexão está organizada em dois momentos. No primeiro aborda a constituição da legalidade para a formação de professores e no segundo momento trata dos aspectos pedagógicos inscritos no contexto político, cultural e econômico da realidade escolar.

\section{IMAGENS DAS POLÍTICAS PÚBLICAS: REAIS OU VIRTUAIS?}

Quanto à questão legal, muitos avanços foram alcançados. As diretrizes nacionais para formação de professores para a educação básica, pautada na Lei 9.394/96 e demais diretrizes curriculares para esse nível de ensino, fortaleceu as licenciaturas direcionando estruturalmente os cursos de formação de professores uma vez que as licenciaturas centram a formação no estudo etapista de conteúdos, e consequentemente menosprezam a formação profissional.

De acordo com as Diretrizes para a Formação de Professores da Educação Básica (BRASIL, 2001, p. 10):

\footnotetext{
${ }^{3}$ Imagens reais são sempre invertidas e podem ser projetadas em uma tela. Espelhos côncavos geralmente produzem imagens reais e invertidas. São usados como espelhos para barbear, refletores em lanternas e faróis de automóveis, e também por médicos e dentistas. Atuam como espelhos convergentes. Espelhos convexos atuam como espelhos divergentes. Sempre produzem imagens virtuais, eretas e diminuídas Espelhos convexos são usados como espelhos retrovisores por motoristas em veículos e como refletores nos postes de luz de rua. http://br.syvum.com/cgi/online/serve.cgi/materia/fisica/espelhos_curvos.html

Revista de Ciências Humanas | FW | v. 15 | n. 24 | p. 20-32 | Jul. 2014 Recebido em: 15 abr. 2014 Aceito em: 28 jul. 2014
} 
A formação de professores fica, geralmente, restrita à sua preparação para a regência de classe, não tratando das demais dimensões da atuação profissional como sua participação no projeto educativo da escola, seu relacionamento com alunos e com a comunidade. Ficam ausentes também, freqüentemente, as discussões sobre as temáticas relacionadas mais propriamente ao sistema educacional e à atuação dos professores, restringindo a vivência de natureza profissional.

Entende-se, pelo exposto, que o curso de licenciatura ao conferir licença ao professor precisa estar integrado a educação básica, considerando que muitos acadêmicos já possuem experiência nesse nível de ensino.

Novas demandas e desafios estão postos para a escola e, obviamente, para os seus profissionais, principalmente quanto à ampliação das funções do professor, no reconhecimento da complexidade do ato educativo, visto que o trabalho pedagógico da escola está organizado na lógica dos currículos padronizados e uniformes.

Nessa perspectiva, verifica-se uma contradição na Lei de Diretrizes e Bases da Educação Nacional (LDBEN), referente à melhoria da qualidade do ensino da educação básica. Ao tratar da formação inicial do professor, a LDBEN aponta políticas que levam ao aligeiramento e à flexibilização da formação, em decorrência das especificidades que o quadro educacional brasileiro apresenta.

Esse círculo vicioso, em que se verifica uma interdependência entre a qualidade do ensino na educação básica e a formação do professor, se ancora no ideal da "teoria do capital humano", na qual a função da escola se reduz à formação de recursos humanos para o mercado. Araújo (2008, p. 63) fortalece esse raciocínio ao afirmar:

\footnotetext{
Em decorrência das transformações no mundo do trabalho, da reedição da Teoria do Capital Humano e também por influência das orientações neoliberais, a política governamental põe a educação em posição de centralidade para a incorporação da sociedade no processo de produção. Com isso, estabelece-se uma prerrogativa da função docente como um dos elementos centrais para o cumprimento desse processo produtivo, o qual passa a ser, juntamente com a escolarização formal, pedra angular nesse processo.
}

As transformações trouxeram a necessidade de mudanças em vários setores da sociedade. A educação foi um setor no qual tais mudanças se fizeram presentes não só pela sua condição de formadora de mão de obra para um mercado com novas exigências, como também pelo fato destas transformações exigirem legitimidade e aceitação da população. Essa

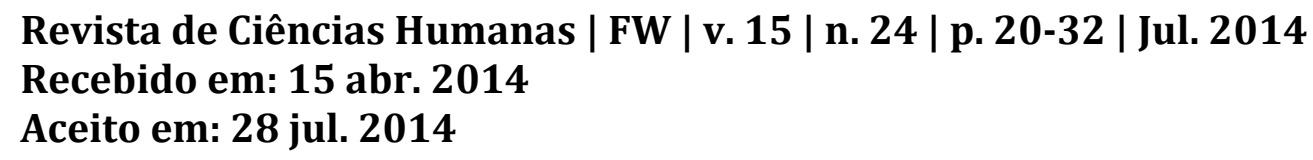


construção de hegemonia é essencialmente pedagógica; é construção e difusão de um novo senso comum, como afirma Gentili (1996).

O sistema educacional, portanto, tem um papel importante a desempenhar, que é o de contribuir sistematicamente para que a população aceite e até defenda as mudanças inspiradas no pensamento neoliberal. Não é por acaso, portanto, que a maioria dos países, passa por reformas educacionais.

As ideias básicas das reformas são também globalizadas, para a consolidação das quais contribui significativamente o Banco Mundial, considerado um dos intelectuais coletivo dessas reformulações.

O pacote de reforma educativa proposto pelo Banco Mundial para os países em desenvolvimento pressupõe alguns desafios a serem superados. Um deles é a melhoria da qualidade, no sentido da eficiência da educação. Convém notar que qualidade, para o Banco Mundial, localiza-se no rendimento escolar do aluno e é resultado de determinados insumos que intervêm na escolaridade (TORRES, 1996). São recomendados investimentos especiais em alguns desses insumos, entre os quais se encontra "a melhoria do trabalho do professor". Logo, o professor é concebido como um insumo, não como o sujeito histórico, que a partir de sua mediação dirige o processo de ensino e aprendizagem.

Na qualidade da educação a sinonímia é eficiência, traduzida por resultados estatísticos sobre números de matrículas, evasão, aprovação dos estudantes. Para o Banco Mundial trata-se de atuar de modo simultâneo sobre os aspectos administrativos, financeiros, curriculares e pedagógicos. A eficiência do sistema deve ser demonstrada em todas as instâncias, mediante a adoção de critérios de mercado, a vinculação com o setor privado.

As reformas educacionais, impostas por esta e outras agências financeiras, também estabelecem regras de adequação do currículo às exigências da globalização mediante a renovação de conteúdos, a capacitação de professores para a mudança, a incorporação de tecnologias teleinformática e a avaliação constante dos resultados, as reformas também exigem dos países a escolha entre a educação “com o professor" ou "sem o professor": capacitar os professores ou apostar nos textos, na televisão, na tecnologia informática. (PNUD, 1999).

No âmbito da formação de professores, não só em seus estágios iniciais nas licenciaturas, mas também na formação continuada para docentes em serviço, é preciso reconhecer que a maior parte das iniciativas oficiais tem se centrado na concepção de um 
aperfeiçoamento individual do docente, sem ter o objetivo de inseri-lo no contexto institucional em que concretamente trabalha, ou seja, na escola (AZANHA, 1987).

Essa lógica determinista aponta a necessidade de repensar a formação inicial e continuada, tendo como eixo de análise as políticas de formação. No entanto, os debates sobre o tema privilegiam as denúncias do caráter pragmático e clientelista dos projetos oficiais, em que se constatam a diminuição do tempo dos cursos de formação de professores e, conseqüentemente, a possibilidade de expansão do setor privado nessa área de formação.

A importância dada à questão da formação, pelas políticas atuais, tem por objetivo elevar a qualidade da educação nos países em desenvolvimento. Segundo Freitas (1999), essa qualidade acaba privilegiando a capacitação em serviço e estimulando as modalidades a distância. Desse modo, assiste-se à definição de medidas, na área de formação, que visam à elevação do nível de escolaridade dos professores que atuam nas primeiras séries do ensino fundamental.

Para alcançar tais objetivos, as seguintes medidas foram executadas: a regulamentação que estabelece a complementação pedagógica de qualquer graduado para atuar na educação básica; o advento do curso normal superior; a regulamentação dos cursos seqüenciais e a elaboração das diretrizes curriculares.

Posterior à Lei de Diretrizes e Bases, o Decreto $n^{\circ} 3.860$, de 9 de julho de 2001 (BRASIL, 2001), estabeleceu que as Instituições de Ensino Superior podem assumir diferentes formatos: universidades, centros universitários, faculdades integradas, faculdades e institutos superiores ou escolas superiores. Na opinião de Freitas (1999, p. 20), “com essas distinções, e mantendo-se a exigência da pesquisa apenas nas universidades, institucionalizase a distinção entre universidade de ensino e universidade de pesquisa". Ou seja, a formação do professor fica a margem do tripé ensino-pesquisa-extensão.

A LDBEN, todavia, garante uma diversidade de espaços de formação, possibilitando ao Ministério de Educação, através do Conselho Nacional de Educação (CNE), a formulação de novas proposições e formatos profissionais. Para tal foram previstos os Institutos Superiores de Educação, cuja tarefa é de formar professores que atuem na educação básica e a de proporcionar formação pedagógica aos portadores de diplomas de educação superior. 
Volta-se, assim, aos antigos Esquemas I e II $^{4}$, bem como à formação continuada em diversos níveis. Convém ressaltar que essa iniciativa já havia sido rechaçada no VIII Encontro Nacional da Anfope (1996, p. 19) que a considerava "desvinculada da pesquisa e da extensão, centrada no ensino, subtraída da ambiência universitária, além de contrariar as políticas de valorização e profissionalização do magistério". Uma formação insólita e desproporcional às exigências formativas da sociedade contemporânea.

Na verdade, essa abertura na legislação possibilitou que o governo e os empresários do ensino criassem esses cursos como forma de baratear custos e de atender às determinações legais no tocante à habilitação de professores em nível superior. As conseqüências já são por demais conhecidas: a privatização desenfreada do ensino, o aligeiramento da formação pela simples capacitação técnica.

Outra medida discriminatória em relação aos cursos de formação de professores é a Resolução CP nº1 (BRASIL, 1999), de acordo com a qual a carga horária mínima é de 3.200 horas, podendo, com base na experiência e na formação anterior dos alunos, ser reduzida para até 1.600 horas. Em 2002, com a revogação dos parágrafos $2^{\circ}$ e $5^{\circ}$ do artigo $6^{\circ}$, do parágrafo $2^{\circ}$ do artigo $7^{\circ}$ e do parágrafo $2^{\circ}$ do artigo $9^{\circ}$ da Resolução $C P n^{\circ} 1$, pela Resolução CNE/CP n 2 (BRASIL, 2002), a carga horária mínima de uma licenciatura passa a ser de 2.800 horas, podendo ser reduzida, caso o aluno exerça atividade docente regular na educação básica a 200 horas.

Mesmo considerando as urgências e dificuldades financeiras nos processos de formação, percebe-se nas propostas oficiais para formação de professores uma preocupação com a habilitação rápida e barata. Afinal, o número de professores sem a formação mínima exigida ainda é grande, o que resulta em um processo muito mais de titulação do que de qualificação. Constitui-se em última instância, em uma resposta aos acordos firmados no contexto internacional. Nesse panorama, é claro, legitimam-se as desigualdades. Por falta de oportunidades, a grande maioria dos que concluem a educação superior tem estudado em instituições cuja formação se dá em modalidades frágeis - em que não se valoriza a produção do conhecimento através da pesquisa -, numa perspectiva exclusivamente emergencial e excludente. Diante dessa problemática, Kuenzer (2007, p. 1170), ao comentar a estratégia usada para disponibilizar/negar o conhecimento, afirma que:

\footnotetext{
${ }^{4} \mathrm{Na}$ emergência em obter profissionais para atuarem no magistério na década de 1970 foram organizados cursos, por força de portaria, denominados esquema I e II. Estes cursos ofereciam formação didática e pedagógica para habilitar o professor em duas situações: bacharéis e concluintes do curso técnico de nível médio.
}

Revista de Ciências Humanas | FW | v. 15 | n. 24 | p. 20-32 | Jul. 2014 
Ao invés da explícita negação das oportunidades de acesso à educação continuada e de qualidade, há uma aparente disponibilização das oportunidades educacionais, por meio de múltiplas modalidades e diferentes naturezas, que se caracterizam por seu caráter desigual e, na maioria das vezes, meramente certificatório, que não asseguram domínio de competências cognitivas complexas vinculadas à autonomia intelectual ética e estética.

Além das pontuais reflexões de Kuenzer, percebe-se, por parte do atual governo, a continuidade das políticas de formação focalizadas, reafirmando modalidades de formação duvidosas, equivocadas ou nem sempre desejáveis. Vale como exemplo o caso da educação a distância considerada, legalmente, como uma das estratégias de acesso à educação. É o que pode ser verificado na LDBEN, artigo 80, no Título VIII: “O Poder Público incentivará o desenvolvimento e a veiculação de programas de ensino a distância, em todos os níveis e modalidades de ensino, e de educação continuada". (BRASIL, 2012, p. 41).

O parágrafo quarto complementa destacando o tratamento diferenciado para a educação a distância com garantia de transmissão mais barata em canais comerciais, além da liberação de canais educacionais exclusivos e a franquia de horários em canais comerciais No entanto, na prática a consolidação desta modalidade de educação acontece precariamente, carecendo ser repensada.

A tecnologia, com suas vantagens e benefícios inegáveis, deve ser usada como mais um instrumento de auxílio aos profissionais da educação em suas práticas pedagógicas. Porém não é esse tratamento que tem sido dado. A modalidade de formação à distância, que, a princípio, surgiu como exceção, tornou-se regra. Ou seja, hoje é uma política de Estado para os programas de formação de professores em serviço, incentivado pela criação de pólos municipais da Universidade Aberta do Brasil $^{5}$ (UAB), que fortalece as instituições privadas, priorizando o aspecto massificador na titulação em nível superior. Com base nessa perspectiva, Freitas (2007, p. 1209) alerta:

Este modelo, desenvolvido à distância através de mídias interativas e novas tecnologias da informação e comunicação, se organiza em projetos de cursos que partem do trabalho dos professores, exclusivamente de sua dimensão prática, reduzindo as possibilidades da mediação pedagógica necessária no processo de ensino.

\footnotetext{
${ }^{5}$ Em 2006, foi criada a Universidade Aberta do Brasil pelo Decreto $\mathrm{n}^{\mathrm{o}} 5.800$ para expandir a oferta de curso superior e programas e atender o interior do país. A prioridade é ampliar cursos de Licenciatura e programas de formação continuada. Os cursos são oferecidos pelos convênios estabelecidos entre Universidades públicas e o Ministério da Educação.
}

Revista de Ciências Humanas | FW | v. 15 | n. 24 | p. 20-32 | Jul. 2014 
O que se observa hoje é uma constante expansão dos pólos da UAB sob a justificativa do difícil acesso à educação superior, especialmente pelas classes menos favorecidas, geralmente residentes em lugares em que não há formação nesse nível de ensino. Parece claro, porém, que fortalecer a UAB, pode levar à criação de uma concepção de formação de professores unicamente centrada no ensino e desvinculada da pesquisa e extensão. Do mesmo modo como os Institutos Superiores de Educação foram caracterizados como instituições de ensino de caráter técnico-profissional, esse novo formato de instituição para formação de professores não descarta a possibilidade da efetivação de políticas de formação baseadas nas técnicas, na valorização do imediato, do aplicável e útil. Resultado: essas instituições se colocariam num patamar inferior ao das universidades, que, por princípio, dedicam-se ao ensino, pesquisa e extensão.

Após essas imagens referidas sobre a discussão legal nos reportamos para a complexa prática do professor, numa breve incursão.

\section{IMAGENS ESCONDIDAS, IMAGENS REFLETIDAS}

Tratando da formação docente, Antunes (2001, p. 4), compara o professor com o marinheiro dos séculos XV e XVI pela seguinte afirmação:

[...] O professor é o novo marinheiro dos tempos que chegam. [...] Ser professor, hoje, é ser vítima de uma profissão difícil e mal compreendida, contudo com a extrema nobreza e dignidade daqueles que têm o privilégio único de anunciar os novos tempos.

Tal afirmativa auxilia na reflexão sobre o grande desafio especialmente, dos últimos trinta anos, da formação docente: problemática, historicamente construída e, em evidência.

Segundo, Cardoso (2003) a prática do magistério é antiga e a preocupação com a educação do homem é anterior ao aparecimento da escola. Enquanto um projeto explícito de transmissão de cultura, a docência é um fenômeno dos tempos modernos e a criação de um curso com a finalidade de formar professores emerge num amplo processo de disciplinarização dos sujeitos e dos conhecimentos. Assim sujeitos e saberes são especificados, classificados, hierarquizados e normatizados.

Revista de Ciências Humanas | FW | v. 15 | n. 24 | p. 20-32 | Jul. 2014 
Antunes (2001, p. 16), através de uma crônica relata a história de Dona Geralda, uma diarista que, deveras fascinada, desejava contar a todos que estava trabalhando para uma pessoa merecedora de apreço. Ao encontrar-se com a amiga Romilda pediu que adivinhasse para quem trabalhava. A amiga arriscou dizendo nomes de artistas, mas Dona Geralda explicou:

[...] Não, Milda. A pessoa não é importante porque aparece na televisão. Para dizer a verdade, ela é importante pela profissão que tem. Imagine, Milda, que eu agora trabalho na casa de um professor-... uma pessoa que ensina as outras pessoas e que, é lógico, deve saber muita coisa. Você nem imagina a quantidade de livros que tem na casa dele! Se ele leu a metade daquilo tudo, acho que sabe até mais que o Presidente da República. Eu até acho que fiquei mais importante porque estou trabalhando na casa de uma pessoa assim, tão importante.

$\mathrm{O}$ autor enfatiza que a mulher do professor ou qualquer outra pessoa que soube da tamanha admiração de Dona Geralda deixaram-na seguir com a ilusão de tanto prestígio para a profissão docente e, conclui salientando que somente o professor não ficou sabendo do julgamento de nobreza conferido a ele pela diarista, pois talvez tivesse alertado-a sobre o quanto a profissão é desvalorizada.

Essa crônica nos alerta, entre outras coisas, para a valorização da profissão através de imagens escondidas, ou seja, nas entrelinhas, no dia-a-dia escolar, no encontro com egressos é que essas imagens podem ser desveladas. Cada docente precisa valorizar-se na indumentária, no vocabulário verbalizado, na rigorosidade dos trabalhos que faz e recebe, na seriedade ao avaliar, na disponibilidade para criatividade e no amor pelo magistério.

Nesse sentido, se quer destacar a importância da criticidade no processo de ensino e aprendizagem. A postura crítica do professor faz a diferença no tratamento dos conteúdos curriculares.

Freire (1996, p. 103) é enfático ao afirmar que: “[...] quanto menos criticidade em nós, tanto mais ingenuamente tratamos os problemas e discutimos superficialmente os assuntos." Destaca que, para ensinar é preciso criticidade, ao contrário da ingenuidade, a criticidade na prática educativa desenvolve a curiosidade crítica, desmedida e indignada com as problemáticas sociais. (FREIRE, 2003)

De acordo com esse raciocínio destaca-se a ética enquanto princípio norteador do trabalhado docente. Para Severino (2001) a exigência ética compromete a formação e atuação docente, pois numa sociedade desigual a desumanidade é gritante. Portanto, a formação do

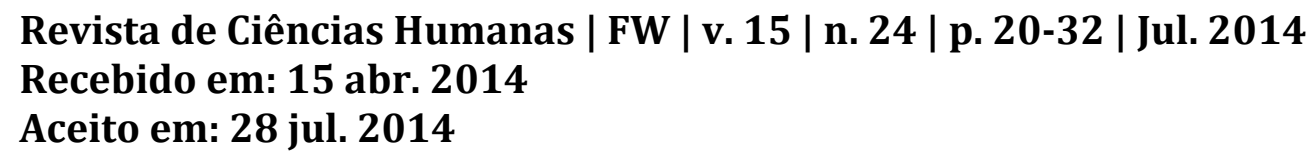


educador deve basear-se politicamente na presença da ética, contrariando ao senso comum de que o professor é um sacerdote. Ao contrário, o professor é formador de opinião e provoca outras críticas como: crítica à estrutura de trabalho; crítica ao autoritarismo disfarçado; crítica aos programas de televisão; crítica aos conteúdos programáticos e, autocrítica.

Segundo Freire (2003) não é possível pensar a educação fora da ética. O papel social do professor é definido pela instituição na qual atua. Ao atuar numa instituição escolar compete ao educador aprimorar seu trabalho. Nessa direção, a prática educativa é destacada pela dimensão ética da competência profissional. O compromisso profissional do fazer pedagógico torna-se um fazer político com uma visão crítica da realidade e da prática educativa quando extrapola a ingenuidade da neutralidade.

Um grande desafio ao professor nos dias atuais é o combate ao pensamento da racionalidade técnica engendrado na sociedade capitalista e global. Essa visão ideológica produz um procedimento racional na mesma racionalidade na qual somente o imediato, o útil e o necessário tem sentido.

Freire (2003, p. 33) afirma que "a prática educativa tem de ser, em si, um testemunho rigoroso de decência e de pureza".

Pode-se afirmar que a imagem da boa formação deve estar calcada nos saberes necessários para a prática docente cuja formação seja cimentada na ética e estética, na competência profissional, no respeito à identidade cultural e na reflexão crítica da prática pedagógica. E ainda a rejeição de toda e qualquer forma de discriminação.

A formação escolar é um campo de oportunidades para as pessoas realizarem seus projetos e sonhos de vida. Dessa forma, entende-se que o trabalho do professor pode contribuir para esse fim.

No que se refere à formação inicial de professores para a educação básica, é consenso que somente aqueles preparados e comprometidos dão sustentação para o aperfeiçoamento da educação básica. Cabe destacar a questão histórica, socialmente legitimada, da importância dos cursos de bacharelados em detrimento das licenciaturas, principalmente quando os cursos de formação de professores não apresentam uma sólida articulação entre conteúdos pedagógicos e de ensino. Durante a formação docente, é indispensável ao acadêmico vivenciar uma construção autônoma do conhecimento e valorização de seu conhecimento prévio. O desafio dos professores universitários é programar atividades reflexivas aos

\section{Revista de Ciências Humanas | FW | v. 15 | n. 24 | p. 20-32 | Jul. 2014 Recebido em: 15 abr. 2014


acadêmicos, no sentido de que os mesmos sintam-se mais preparados para lidarem com o complexo processo de ensino e aprendizagem na educação básica.

Neste sentido, a universidade tem o desafio de rever a formação oferecida e refletir sobre as ações efetivadas para atender ao novo paradigma educacional que prega a função do professor como mediador do conhecimento. O exercício do magistério apresenta diferentes nuances tendo a humanização como preocupação primeira. A identidade do professor pensada a partir dos sujeitos sociais heterogêneos está vinculada a uma cultura mediada pelo trabalho; enquanto um processo dinâmico, provocador e desafiante de formação humana.

\section{CONSIDERAÇÕES FINAIS}

Acreditamos que a formação de professores passa por uma ressignificação e neste contexto está em xeque a qualidade formativa, pois com base no exposto a aparente preocupação com a qualidade do ensino na educação básica entra em contradição com a concepção de um ideal formativo desde os anos 1990 e que perdura até os dias atuais, quando se legitima uma política de formação de profissionais da educação, em serviço e/ou a distância, em pólos da $\mathrm{UAB}$, de forma aligeirada, com duração reduzida e sem articulação entre ensino, pesquisa e extensão.

Ao se constatar o continuísmo das ações governamentais das últimas décadas, em relação à formação dos professores, percebe-se claramente a falta de prioridade no tocante a investimentos e recursos orçamentários, uma vez que as políticas de formação ao longo dos anos são incorporadas pelos governantes como problemas emergenciais. Isso se reflete na oferta de diferentes modalidades de formação, cujas diferenças de apropriação dos conhecimentos científicos são mascaradas pelo discurso da igualdade de oportunidades.

Numa imagem côncava a superfície refletora é interna e na convexa é externa. Fazendo uma analogia se pode afirmar que a formação de professores produz imagens côncavas e convexas. Externamente é perceptível um crescimento na oferta de cursos e adequações pedagógicas, por outro lado, internamente, a imagem é de pauperização.

\footnotetext{
ABSTRACT: The text proposes a reflection on the teacher formation in basic education. Discusses some contradictions in the formation pattern offered, like the research question while discourse to form teacher-researcher as opposed to the curriculum of the courses in which the development of research is absent. The discursive thread is the dialogue about teacher while concave and

Revista de Ciências Humanas | FW | v. 15 | n. 24 | p. 20-32 | Jul. 2014 
convex images in order to understand the images produced by real or virtual institutions. At first, the article points out some concerns with regard to public policy undergraduate. At the second time addresses the formation as professional development process taking criticism and ethics as formative pillars.

Keywords: Basic Education. Undergraduate Program. Teacher formation.

RESUMEN: El texto propone una reflexión sobre la formación de profesores de la educación básica. Discute algunas contradicciones en la oferta del modelo de formación puesto, como la cuestión de la investigación en cuanto discurso de formar profesor-investigador en oposición al currículo de los cursos en los cuales el desenvolvimiento de investigación está ausente. Tiene como hilo conductor el diálogo sobre formación de profesores en cuanto imágenes cóncavas y convexas, en el sentido de entender las imágenes, reales o virtuales producidas por las instituciones. En un primer momento el artículo apunta algunas inquietudes en relación a las políticas públicas de cursos de graduación y en un segundo momento aborda la formación en cuanto proceso de valorización profesional teniendo la crítica y la ética en cuanto pilares formativos.

Palabras-clave: Educación Básica. Cursos de Graduación. Formación de Profesores.

\section{REFERÊNCIAS}

ANTUNES, Celso. Marinheiros e professores: crônicas simples sobre escola, ensino, disciplina, inteligências emocionais, criatividade, construtivismo, inteligências múltiplas, professores, alunos. 8.ed. Petrópolis: Vozes, 2001.

ARAÚJO, Nataniel da Vera-Cruz Gonçalves. O Normal Superior telepresencial e a trilogia: política educacional, formação de professoras (es) e educação a distância. Dissertação (Mestrado em Educação) - Universidade Federal do Maranhão, São Luís, 2008.

AZANHA, J. M. Educação: alguns escritos. São Paulo: Cia Editora Nacional, 1987.

BRASIL. Lei de Diretrizes e Bases da Educação Nacional, no 9394, de 20 de dezembro de1996, que estabelece as diretrizes e bases da educação nacional. 7. ed. Brasília: Câmara dos Deputados, Edições Câmara, 2012. Disponível em:

<http://www.planalto.gov.br/ccivil_03/leis/19394.htm>. Acesso em: janeiro de 2014.

Diretrizes para a Formação de Professores da Educação Básica em Nível Superior. Brasília: Ministério da Educação, 2001.

Resolução CP $\mathbf{n}^{0}$ 1, de 30 de setembro de 1999. Institui as diretrizes nacionais para o ensino infantil. Brasília: Ministério da Educação, 1999.

Ministério da Educação. Decreto n 3.860, de 9 de julho de 2001. Brasília, 2001. Disponível em: <http://portal.mec.gov.br/sesu/arquivos/pdf/DecN3860.pdf>. Acesso em: janeiro de 2014.

Revista de Ciências Humanas | FW | v. 15 | n. 24 | p. 20-32 | Jul. 2014 
Resolução CNE/CP no ${ }^{2}$, de 19 de fevereiro de 2002. Institui as diretrizes nacionais para a formação de professores da educação básica, em nível superior, cursos de licenciatura, de graduação plena. Brasília, 2002.

CARDOSO, Lilian A. Maciel. Formação de professores: mapeando alguns modos de ser professor ensinado por meio do discurso científico-pedagógico. In: PAIVA, Edil V. de. Pesquisando a formação de professores. Rio de Janeiro: DP\&A, 2003. p.11-46.

ENCONTRO NACIONAL DA ANFOPE, 8. Documento final. Belo Horizonte, 1996.

FARIAS, Flávio Bezerra de. O Estado capitalista contemporâneo: para a crítica das visões regulacionistas. 2. ed. São Paulo: Cortez, 2001. (Coleção Questões da Nossa Época).

FREIRE, Paulo. Pedagogia da autonomia: saberes necessários à prática educativa. 28. ed. São Paulo: Paz e Terra, 2003.

Educação como prática da liberdade. 22. ed. São Paulo: Paz e Terra, 1996.

FREITAS, Helena Costa Lopes de. A reforma do ensino superior no campo da formação dos profissionais da educação básica: as políticas educacionais e o movimento dos educadores. Educação \& Sociedade, Campinas, v. 20, n. 68, p.17- 44, 1999.

A (nova) política de formação de professores: a prioridade postergada. Educação \& sociedade, Campinas, v. 28, n. 100, p. 1203-1230, 2007.

GENTILI, Pablo. Como reconhecer um governo neoliberal? Um breve guia para educadores. In: HERON, Luiz; AZEVEDO, José (Orgs.). Reestruturação curricular: teoria e prática no cotidiano da escola. Petrópolis, RJ: Vozes, 1996.

KUENZER, Acácia Zeneida. Da dualidade assumida à dualidade negada: o discurso da flexibilidade justifica a inclusão excludente. Educação \& Sociedade, Campinas, v. 28, n. 100, p. 1153-1178, 2007.

PNUD. Los retos educativos del futuro. Estado de la Educación en América Latina y Nel Caribe. Costa Rica: Guilá Editora,1999.

SEVERINO, Antônio Joaquim. Educação, sujeito e história. São Paulo: Olho D`agua, 2001.

TORRES, Leonor Lima. Cultura organizacional escolar. Representação dos professores numa escola portuguesa. Oeiras: Celta, 1996.

Revista de Ciências Humanas | FW | v. 15 | n. 24 | p. 20-32 | Jul. 2014

Recebido em: 15 abr. 2014

Aceito em: 28 jul. 2014 